\title{
PHILOLOGY
}

\section{AN ATTEMPT TOWARDS THE APPROPRIATE METHODS FOR QUALITATIVE RESEARCH}

\author{
Huseynova Arifa \\ Azerbaijan State Oil and Industry University, Azerbaijan \\ DOI: https://doi.org/10.31435/rsglobal_ws/31072019/6597
}

\section{ARTICLE INFO}

Received: 27 May 2019

Accepted: 12 July 2019

Published: 31 July 2019

\section{KEYWORDS}

defined problems, comprehend, reproducibility, crystalline structure, creative mentality, team approach.

\begin{abstract}
An analysis of research process indicates that it comprises in combination, the following elements: creative mentalities, properly defined problems, semantic problem -solving procedures, and certain types of possible solutions. All these elements are necessary and sufficient. Therefore, the most efficient relative utilization of each will make for the most desirable research procedure in any given application. The purpose of this paper is to discuss possible principles to be used in arranging these elements in an efficient manner, which will be useful in comprehending the present practice and the future of research. It should be noted at the start that these principles, intuitively and deductively inferred from an investigation of the characteristics of the research elements are to be considered tentative; the implication is not that they are necessarily invariant in research, but that the elements from which they stem are the same within any reference frame.
\end{abstract}

Citation: Huseynova Arifa. (2019) An Attempt Towards the Appropriate Methods for Qualitative Research. World Science. 7(47), Vol.2. doi: 10.31435/rsglobal_ws/31072019/6597

Copyright: (C) 2019 Huseynova Arifa. This is an open-access article distributed under the terms of the Creative Commons Attribution License (CC BY). The use, distribution or reproduction in other forums is permitted, provided the original author(s) or licensor are credited and that the original publication in this journal is cited, in accordance with accepted academic practice. No use, distribution or reproduction is permitted which does not comply with these terms.

\section{Introduction.}

\subsection{Solution of Research Problems}

Principles for guiding research will be determined to some extent by the answer to the question. What solution does a research problem consist of? To guide the process of research efficiently, we must decide the characteristics of an answer must have. For example, if we are to define a solution to a given problem as that resolution of the environmental situation which the individual or group acts as though it had achieved a "truthful" answer, we have not bounded the process sufficiently to judge the efficiency of the procedure. If a completely incorrect solution serves as the basis for action, it seems desirable that we should be able to say that the process used had a very low, if not a "negligible", measure of efficiency. Conversely, it appears desirable- and reasonable - to say that the more nearly correct the solution obtained is, the more efficient is the research process utilized.

A solution to a research problem has been obtained when the individual or group is able to overcome the gap or obstacle in the particular situation. More precisely, the efficient solution comprehends that measure of reproducibility which completely resolves all the elements in the given problem. An incorrect solution would have a measure reproducibility of zero (this is a probability measure and does not imply complete no reproducibility), and the correct solution possibly have total. The research process must be so organized as to give solutions of the required order of reproducibility magnitude. Thus, as among research groups, that one will be most efficient, which resolves most of the elements of particular problem. Reproducibility implies that solution may be more or less complete. The lack of reproducibility doesn't necessarily mean that the solution proposed has no value. If the elimination of impurities in the crystalline structure has no effect on the observable 
variables involved in the fracture, the solution has no measure of reproducibility with respect to this problem. The value of solution to a research problem may make itself apparent in various ways. The resolution of a particular problematic situation will, in turn, create new problems. The answer which is satisfactory in a given instance may be focusing of the individual or group attention upon an element or elements of finer detail which were not discernible in the original problem. Such an answer also has implications of reproducibility in that it serves as a basis on which further action is predicted.

The utility of a particular solution to a problem, obtained through research, in enabling an individual or a group to take satisfactory action based upon the future results predicted, is the measure of the over- all efficiency of the process. Measures of this efficiency are no doubt difficult to obtain. Nevertheless, it is apparent that two possible types of solutions should be readily recognizable: gross errors and solutions with high degrees of reproducibility. If such a system of evaluating the efficiency of a research organization were practiced, refinements could be developed, based on experience and observation, which would better indicate operational characteristics and the relative difficulty of problems than the qualitative methods for such evaluation now in use. Quantitative means are currently in use in some industrial organizations, for example, to measure the results of research, but these are generally based upon some type of profit -and -loss calculations which are at least once removed perhaps more so- from the research process itself. The measurements we have defined are in some degree related to these latter, but they are in no wise the same. Direct application of these concepts to industrial research will not be considered here. The other elements of the research process must be considered from the standpoint of the solutions reached. Any principles inherent in the utilization of each of the components must be directed toward the production of reproducible solutions. As previously noted, the research process begins with a problem of a particular type; either the data or the methods of solution are not simultaneously, or, if known, they are not desirable. Also, systematic methods of solution begin with the problem, its analysis and definition. From the standpoint of ultimate results, this problem analysis is quite possibly the most important element in the entire process.

The first step in the analysis of any problem presented to an individual or group for solution by the research process is a determination as to whether or not the problem is one suitable for the organization. For example, if it is a routine problem for which both the data and method are available and adequate to give the solution with an acceptable risk of error, it would be inefficient for an organization established for research purpose to extend its resources in attaining a solution. A research organization for the purpose of using creative abilities to solve research problems, and the decision as to whether the problem is suitable or not is often relatively easy to make. The principle should be observed that a research organization should undertake the solution only of research problems. The simplicity and obviousness of this concept are deceptive: in industrial organizations, particularly, much work is done in the name of research which involves none of its elements.

There is, of course, no different art in the adjustment of an organization to the various types of research problems than in setting up the organization to solve problems efficiently in the first place. The principles are the same. The only change is the situation to which they must be applied. Nonetheless, the application of the research organization to various types of problems requires a suitable diagnosis of the situation in advance. Clearly, organization which undertakes the solution of a problem of organized complexity as though it were one of simple variables is proceeding most inefficiently. Personnel, techniques, and other resources required are apt to be quite different and, unless these are provided in advance, efficient operations will not be possible. In general, this same analysis should be indicative of the various elements of the problem.

Most research problem particularly those of industry, comprehend more than one specialized branch of science. This is true for problems of simple variables as well as for others. From our standpoint in this study, this means that a research problem can and should be defined in terms of various sub-ordered problems which may or may not fall within several specialized branches of sciences. In the analysis of any problem it is extremely important that the structural elements be distinguished. These elements may be quite diverse, but the thought- directing vectors derived from their recognition are essential to the creative solution. Each of the structural elements may constitute a sub problem, and in so far as the usually research organization is concerned; it is unlikely that any one individual specialist will have the necessary background, knowledge, and creative ability to solve all of them. This distinguish between the structural elements of the problem is the definitive requirement of problem analysis, and it must be undertaken even though the problem itself is somewhat vague or hazy. This is simply to say that the process of solution must start somewhere, and it will be most efficient to begin the process with those resources which will ultimately be involved before the 
solution is reached, if possible. The implication is not intended here that these elements can always be solved as independent entities, although this is sometimes possible; what is intended is that the problem shall be analyzed and resolved into some clear pattern of its elemental parts.

The aim of this study is to discuss possible principles to be used in arranging these elements in an efficient manner, which will be useful in comprehending the present practice and the future of research.

\section{Study.}

\subsection{The research team.}

It is likely that each of the elements can be solved independently; it is more likely that each of the parts must be resolved cooperatively and coordinately, with the specialists operating as a team. The composition of this team should depend upon the priori analysis of the problem. It will be necessary that the members of the team communicate with each other, each seeing his own work in relation to the whole, and each understanding enough of surrounding fields to suggest experiments to those to have the specialized skill to carry them out. The professionalized approach used by most research organizations, is not the most efficient method of solving problems involving a complexity of elements, and the greatest number of industrial problems are of this type. There is a particular composite of creative mentalities which will be most efficient in a given instance.

The ability of an individual to analyze an environmental situation correctly depends in large measure upon a predetermined attitude or set. In this "set" which largely distinguishes the laboratory researcher from, say, the development engineer. This is intuitively recognized throughout research, as indicated by such common statements as "The theoretician has an entirely different viewpoint (attitude)"as compared with the applied scientist. Each time a problem is reoriented and the structural elements reformulated, the attitude which could most profitably be utilized for further analysis may be somewhat different. Obviously no one individual can be expected to have a multiplicity of such sets toward a given problem. A group is more plastic in this respect, since it is quite possible to shift the collective viewpoint or attitude with the requirements of the situation.

\subsection{The collective attitude.}

The collective attitude of the research team selected on the basis of the requirements of the problems, offers, in general, the most efficient group of presuppositions from which to proceed to its solution. On what basis is the group attitude conceived? At no stage in the research procedures can be individual mentalities be completely blank, and each individual will come to the group with his own particular set. How many these different attitudes be subsumed in a collective set? If the analysis of the problem is undertaken on an authoritarian basis, by a director or leader, and transmitted without modification to the group, then one of the advantages of group activity is lost, and except for the quantity of work involved, the research might as well be considered individual. Under exceptional leaders, such a procedure may be and has proved to be quite efficient and can lead to satisfactory solutions. If this transmitted viewpoint is contrary to the collective attitude, the conflict inherent in such a situation could possibly negate the anticipated results of the most brilliant analysis.

In general, the analysis of a problem presented to a group of research workers may be developed in one of the following ways:

1. The analysis may be made completely by higher authority and a predetermined attitude presented to the group.

2. The individuals may work independently, proceeding on the basis of their own presuppositions.

3. Individual ideas may be presented to higher authority, where another "set" will be added (or subtracted) and the synthesis returned as the attitude to be followed.

4. The group, including such higher authority as may be required, may collectively arrive at a satisfactory analysis of the problem for further work. If proper safeguards are provided in the selection of personal and influence of individual personalities, this is the most efficient general principle of operation to be followed at this stage of collective research activity.

The individual creative ability is an essential element in the over-all process we are synthesizing. The selective grouping of such mentalities and the utilization of their individual attitudes to create a more effective group approach have already been discussed with respect to a rational analysis of problems.

\subsection{The individual researcher.}

Probably the most important single element in problem solving is the realization by the researcher that any given problem may differ, from stage to stage in its solution, in method required, and in difficulty of applying that method. It is essential that the abilities of the individuals be such that 
they are capable of assuming the responsibility of solving the problems delegated to them. Clearly, if an individual, as part of a team or alone, is given an obstacle which he is not capable of overcoming, he is not being utilized efficiently. In weighing the ability of individual, it is important to realize that creative mentalities differ, and the types of mentalities required for different problems, or for different stages of the same problem, may differ.

\section{Discussion.}

\subsection{The choice of method:}

The selection of the method will depend upon the analysis of the problem, the individual mentalities involved, and the general character of the team or organization. The efficiency of the process will vary with the suitability of the method. The choice of a method should be considered in the same light as the choice of any other resource. Method is not the be-all and end-all in research, nor is it a random factor whose choice would in no way affect the process efficiency. The selection of method in advance of any analysis and the imposition of this method upon what may be considered fixed entities in the system would be highly inefficient. Similar considerations as those discussed in arriving at a collective attitude toward problems hold in the choice of the manner of their solution. Changes in the attitudes assumed toward a problem, whether of a part or the whole, will occur from time to time as the situation is modified by the action of the researchers.

The choice of method should be made on the basis of the analysis of the obstacle in the environmental situation which is to be overcome, and the total resources available to the research organization to achieve this purpose. The difficulty of establishing valid procedures for the application of value judgments and for the answering of questions of value does not imply that such tests can by any means be eliminated from research procedures. The coordinated combination of judgments of a group selected as best fitted to solve a given problem is probably the best answer that can be given to this question under the present circumstances.

Conclusions. In conclusion, the answer to the question of the most efficient manner of arriving at satisfactory solutions to research problems in a collective organization may be given the following general principles:

1. An active analysis of problem or problems in terms of complexity, attributes, compatibility with the capabilities of the organization, and structural elements or sub problems.

2. Determination of the probable mental, logical, and physical recourses necessary for the achievement of a solution.

3. Continuing reanalysis as results are obtained, and reevaluation of resources required.

4. A unified or cooperative approach utilizing those resources capable of providing a solution.

These principles will provide a means for concerted endeavor and attack upon all types of research problems. An efficient organization is certainly not one in which each individual is doing the same thing. Each individual must be given responsibility for a certain share in the over-all task, his duties must be defined, and his capabilities must be suited to those duties. In addition, he must understand what is required of him. The task of delegating and defining these responsibilities so as to carry out the collective research process in accordance with these principles falls within the province of administration and organization. A knowledge of the background of creative ability and the scientific method is essential as a guide to administering those who advance scientific knowledge by means of research.

\section{REFERENCES}

1. C.E.K.Mees. The Pass of Science New York: John Wiley and Sons 1997,pp.60.

2. J.B.Conant. On Understanding Science. Yale University Press, 1999, p.100.

3. C.W.Churchman. Theory of Experimental Interference, New York: 2001, p. 226.

4. John Dewey, The Quest for Certainly, Intelligence in the Modern World: John Dewey's Philosophy, Joseph Ratner, New York: in 2000, p.318-320. 